\title{
1Occurrence but not intensity of mortality rises towards the climatic 2trailing edge of tree species ranges in European forests.
}

\section{3}

4Running title: European forests mortality

5

6Corresponding author: Marta Benito Garzón

7

8Authors: Alexandre Changenet ${ }^{1}$, Paloma Ruiz-Benito ${ }^{2}$, Sophia Ratcliffe ${ }^{3,4}$, Thibaut Fréjaville ${ }^{1}$, Juliette 9Archambeau ${ }^{1}$, Annabel J. Porte ${ }^{1}$, Miguel A. Zavala ${ }^{5}$, Jonas Dahlgren ${ }^{6}$, Aleksi Lehtonen ${ }^{7}$, Marta 10Benito Garzón¹.

11

12Laboratory origins:

13ㄹIOGECO INRAE UMR 1202 University of Bordeaux, Pessac, 33400, France

$14^{2}$ Departmento de Geología, Geografia y Medio Ambiente, Universidad de Alcala, Spain; and Forest 15Ecology and Restoration Group, Departamento de Ciencias de la Vida, Universidad de Alcala, Spain $16^{3}$ National Biodiversity Network Trust, Nottingham, UK

$17^{4}$ Department of Systematic Botany and Functional Biodiversity, University of Leipzig, Johannisallee 1821-23, 04103 Leipzig, Germany.

$19^{5}$ Forest Ecology and Restoration Group, Department of Life Sciences, Universidad de Alcalá (UAH). 20Edifício Ciencias, Campus Universitario, 28871 Alcalá de Henares, Madrid, Spain.

21 ${ }^{6}$ Swedish University of Agricultural Sciences, 90183 Umeå, Sweden

$22^{7}$ Natural Resources Institute Finland (Luke), FI-00710 Helsinki, Finland

23Keywords: background mortality, die-off mortality, European trees, biogeography, modeling, 24National Forest Inventories, range margins, FunDivEUROPE 


\section{Abstract}

30Aim: Tree mortality is increasing worldwide, leading to changes in forest composition and altering 31global biodiversity. Yet, due to the multi-faceted stochastic nature of tree mortality, large-scale spatial 32patterns of mortality across species ranges and their underlying drivers remain difficult to understand. 33 Our main goal is to describe the geographical patterns and drivers of the occurrence and intensity of 34tree mortality in Europe. We hypothesize that the occurrence of mortality represents background 35 mortality and is higher in the margin than the core populations, whereas the intensity of mortality 36could have a more even distribution according to the spatial and temporal stochasticity of die-off 37events.

39Location: Europe (Spain, France, Germany, Belgium, Sweden and Finland) 40

41Time period: 1981 to 2014 .

42

43Major taxa studied: More than 1.5 million trees belonging to 20 major forest tree species 44

45Methods: We develop hurdle models to tease apart the occurrence and intensity of tree mortality in 46National Forest Inventory plots at range-wide scale. The occurrence of mortality indicates that at least 47one tree has died in the plot and the intensity of mortality refers to the number of trees dead per plot. 48

49Results: The highest mortality occurrence was found in peripheral regions and the climatic trailing 50edge linked with drought, whereas the intensity of mortality was driven by competition, drought and 51high temperatures and was uniformly scattered across species ranges.

52

53Main conclusions: Our findings provide a new perspective in our understanding of tree mortality 54across species ranges. We show that tree background mortality but not die-off is generally higher in 55the trailing edge populations, but whether other demographic traits such as growth, reproduction and 56regeneration would also decrease at the trailing edge of European tree populations needs to be 57explored.

58

59Keywords: Tree mortality, National Forest Inventory, drought, climatic edges, European forests, 60hurdle models, background mortality, die-off mortality 
bioRxiv preprint doi: https://doi.org/10.1101/2020.10.30.362087; this version posted November 1, 2020. The copyright holder for this preprint (which was not certified by peer review) is the author/funder, who has granted bioRxiv a license to display the preprint in perpetuity. It is made available under aCC-BY-NC-ND 4.0 International license.

\section{INTRODUCTION}

63Tree mortality is occurring worldwide (Allen, Breshears, \& McDowell, 2015; IPCC, 2014; McDowell 64et al., 2018). Tree mortality can change forest community, ecosystem dynamics and function, and 65hence alter biodiversity (McDowell et al., 2008). Yet, tree mortality remains difficult to predict at 66large spatial scales (Hartmann et al., 2018) because it is a multi-faceted, stochastic process (Franklin, 67Shugart, \& Harmon, 1987). Background tree mortality is a phenomenon that generally occurs in 68individual trees (Hartmann et al., 2018) and is defined as the local mortality rate in the absence of 69catastrophic events (Csilléry, Seignobosc, Lafond, Kunstler, \& Courbaud, 2013; Franklin et al., 1987; 70McDowell et al., 2018). It is a complex process driven by the combination of climate, forest 71composition, trees interactions and age (Cailleret et al., 2017; Hülsmann, Bugmann, \& Brang, 2017; 72Ruiz-Benito, Lines, Gómez-Aparicio, Zavala, \& Coomes, 2013). In contrast, die-off mortality is a 73local phenomenon where many trees die together in the same environment (Bugmann et al., 2019; 74Mueller-Dombois, 1987). Die-off mortality has been related to heatwaves and climate warming 75including extreme localized events, disturbances or environmental conditions such as intense drought, 76storms or fire (Allen et al., 2010; Breshears et al., 2005; McDowell, 2008), and is exacerbated by pest 77and disease outbreaks (Anderegg et al., 2015; Kurz et al., 2008).

78

79Climate change, especially increases in the number and duration of drought events, has been linked to 80increases in both background mortality rates and the extent of die-off events (Allen et al., 2015; Allen 81et al., 2010; Benito Garzón, Ruiz-Benito, \& Zavala, 2013). However, identifying the drivers of die82off and background mortality along large environmental gradients remains challenging because tree 83sensitivity to biotic and abiotic factors depends on the species identity (Ruiz-Benito et al., 2013), their 84age (Hülsmann et al., 2017) and their ecological strategies (Benito Garzón et al., 2018; Ruiz-Benito et 85al., 2017; Archambeau et al., 2020). 
87In the context of climate change, we could expect an increase of mortality in trailing edge populations

88due to increased drought and rising temperatures (Benito Garzón et al., 2013; Carnicer et al., 2011; 89Purves, 2009; Young et al., 2017). However, very little is known about the differential drivers of 90background tree mortality and die-off events at large geographical scales, and both processes can 91occur throughout the species ranges, in the leading edge, the trailing edge and the core of the species 92ranges (e.g. Jump, Mátyás, \& Peñuelas, 2009; Allen et al. 2010; Greenwood et al. 2017). Although, 93we could expect higher background mortality at the margins than at the core of the distribution 94(Neumann, Mues, Moreno, Hasenauer, \& Seidl, 2017), and most intense events of mortality evenly 95distributed across species ranges (Allen et al., 2015; Allen et al., 2010; Jump et al., 2009; Jump et al., 962017).

97

98Here, we analyze tree mortality of 20 major forest tree species from more than 1.5 million trees 99recorded in the National Forest Inventories from Spain, France, Germany, Belgium (Wallonia), 100Sweden and Finland to understand their patterns along species distribution ranges. We assume that 101the occurrence of mortality found in a plot reflects background mortality whereas the intensity of tree 102mortality found in a plot reflects die-off events. We develop hurdle models of mortality occurrence 103and intensity to understand the effect of climatic marginality defined as areas exhibiting the highest or 104the lowest values of several climatic variables and its interaction with drought. The aims of our study 105are to i) identify the underlying drivers of mortality occurrence and intensity and how they are 106influenced by the marginality of the population, and ii) to evaluate tree mortality occurrence and 107intensity patterns across species distribution ranges. We hypothesize that marginal populations will 108have higher occurrence of mortality than core populations, and that the intensity of mortality will 109show a patchy distribution over spatial range reflecting the stochastic nature of die-off events. 


\section{2.1 National Forest Inventory harmonization}

114We used mortality records and stand variables from National Forest Inventories (NFIs) of five 115countries (Spain, Germany, Finland, Sweden, Wallonia (Belgium)) (harmonized in FunDivEUROPE; 116(Baeten et al., 2013)) and the French National Forest Inventory (harmonized in Archambeau et al., 1172020). The French NFI has temporary plots recorded between 2005 and 2014 whereas the other 118countries have permanent plots sampled several years apart, ranging from 1981 to 2011 (Supporting 119Information Table S1). Data from the six NFIs together cover a latitudinal gradient from $36^{\circ} \mathrm{N}$ 120 (Spain) to $70.05^{\circ} \mathrm{N}$ (Finland).

121

\subsection{Plot-level tree mortality recorded from NFI}

123We used individual tree mortality data for 20 major forest tree species, gathering a total of $1,649,850$ 124trees and 235,394 plots (Supporting Information Table S2) varying from 10 to $263 \mathrm{~cm}($ mean $=28)$ 125diameter at breast height $(\mathrm{DBH} ; \mathrm{cm})$ and with a mean census intervals of 10.7 years ranging from 2 126(29 plots) to 20 years (46 plots). Mortality occurrence was calculated as a binary variable, with zero 127when all trees were alive in the plot and one when at least one tree died in the plot during the census 128interval. Mortality intensity was calculated in each plot as the percentage of trees that died between 129the first and second inventory in the NFIs with permanent plots, divided by the number of years 130between census and calculated at the hectare level. In the French NFI tree mortality per plot was 131calculated as the percentage of trees that died within the five years before sampling in the temporary 132plot. We removed plots with trees recently recorded as harvested or managed between consecutive 133inventories and individual trees under $100 \mathrm{~mm} \mathrm{DBH}$ to make the tree measurements consistent across 134country with different DBH thresholds (Table S1).

\section{5}

136To avoid the potential bias caused by the different years of NFIs campaigns and the different size of 137the plots between the NFIs (Table S1), we upscaled tree mortality from plot to hectare per year using 138a weighted index provided by each NFI and dividing this value by the number of years between 
139campaigns for NFI with repetitive measurements or by five for the French NFI, where mortality was 140estimated for five years (Supporting Information Table S3). The weighted index reflected the size of 141the plot or the density of the grid or both depending on the country (Table S1 and 142http://project.fundiveurope.eu/).

\subsection{Model predictors}

\subsubsection{Indexes of climatic marginality and climatic areas}

146We determined the distribution range of each species using information available from Caudullo, 147Welk, \& San-Miguel-Ayanz (2017) or EUFORGEN (http://www.euforgen.org/). Within each range 148we characterised the climate using a Weighted Principal Component Analysis (WPCA, Benito149Garzón, Leadley, \& Fernández-Manjarrés, 2014) based on 21 climatic variables averaged over the 1502000-2014 time period at each point in a 1 x $1 \mathrm{~km}$ pixel size grid (Supporting Information Table S4). 151The WPCA was calculated using 10,000 randomly selected points within each species ranges. The 152variance explained by the two first axis of the WPCA ranged from $71.53 \%$ to $87.42 \%$ for Fagus 153sylvatica and Larix decidua, respectively, Supporting Information Table S8). Based on the weighted 154scores of the two first WPCA axis we defined three climatic groups: core, transition and marginal 155regions (Supporting Information Figure S1 and Table S5). Species-specific thresholds for attributing 156the core $(\mathrm{C})$, climatic marginal $(\mathrm{M})$ and transition $(\mathrm{T})$ areas were calculated based on the WPCA 157scores (Table S2): values from 0 to $60 \%$ were attributed to core areas, values between 60 and $80 \%$ 158are transition areas and values higher than $80 \%$ are marginal areas.

159To further separate climatic marginal areas (M) into climatic trailing edge (TE) for the southernmost 160one and climatic leading edge (LE) for the northernmost, we used a Discriminant Principal 161Component Analysis (DPCA) and an attribution test to check whether individual points were 162successfully reassigned in their attributed group based on the discriminant functions (Jombart, 2008; 163Figure S1). 
164Finally, NFI plots were linked with the WPCA scores and classified as core (C), leading or trailing

165edge (LE and TE) accordingly. Plots lying in the transition region (T) were not used in the analysis 166(Supporting Information Table S2 and Figures S1,S2).

167

\subsubsection{Climatic data}

169We characterised the long-term climate of each plot with eight climate variables. To make the 170variables comparable between different survey dates and countries, we averaged them over the last 30 171years prior to the first survey (hereafter climatic variables; Table S4) (Fréjaville \& Benito Garzón, 1722018). The eight variables included four temperature-related variables and four precipitation-related 173variables that were uncorrelated and that have been shown to have an effect on tree mortality 174(Archambeau et al., 2020; Benito Garzón et al., 2018; Ruiz-Benito et al., 2017): annual mean 175temperature (bio1), maximal temperature of the warmest month (bio5), winter mean temperature 176(tmean.djf), autumn mean temperature (tmean.son) (temperature variables) \& annual precipitation 177(bio12), precipitation of the wettest month (bio13), precipitation of the driest month (bio14), annual 178water balance (precipitation minus potential evapotranspiration (ppet.mean) (Table S4).

180 In addition, we used the Standardized Precipitation Evapotranspiration Index (SPEI v.2.5 (2017) 181(http:// hdl.handle.net/10261/104742). SPEI is a multi-scalar drought index where negative values 182indicate drier conditions over the timescale considered (from 3 to 48 months), relative to median 183values for a long-term reference period (from 1901 to 2015) (Vicente-Serrano, Beguería, \& López184Moreno, 2010). For each month during the time interval between inventory campaigns, we used 1901 185to 2015 as a reference period and calculated SPEI monthly index considering a period of 12 months 186relative to our reference period. For each plot and based on these monthly data, we calculated the 187annual means and extracted the minimum and mean values for this time period (hereafter SPEI 188variables; Table S4). 


\subsubsection{Stand and competition variables}

191All stand variables were calculated using NFI data, transformed where necessary to meet the model 192assumptions of normality (Supporting Information Table S6): total basal area increment $\left(\mathrm{BAI}_{\mathrm{j}}, \mathrm{m}^{2} \mathrm{ha}\right.$ $\left.193 \mathrm{yr}^{-1}\right)$, calculated as the difference in basal area between two inventory periods for all NFIs except 194France where five years cores were used; mean basal area increment (meanBAI ${ }_{j}, \mathrm{~m}^{2}$ ha $\left.\mathrm{yr}^{-1}\right)$; mean 195diameter at breast height $(\mathrm{DBH}, \mathrm{mm})$, tree density calculated as the number of trees per hectare 196(treenumber, No. trees ha $\left.\mathrm{a}^{-1}\right)$; total $\left(\mathrm{BA}, \mathrm{m}^{2} \mathrm{ha}^{-1)}\right.$ conspecific stand basal area (estimated as the basal 197area of all individuals of the species in the plot, BAcon, $\mathrm{m}^{2} \mathrm{ha}^{-1}$ ) and heterospecific stand basal area 198(estimated as basal area of all individuals excluding the studied species) (BAhetero, $\mathrm{m}^{2} \mathrm{ha}^{-1}$ ).

199The $\mathrm{DBH}, \mathrm{BAI}_{\mathrm{j}}$, meanBAI $\mathrm{j}$ and treenumber were included in the model as proxies of the average age 200(DBH), growth and tree density in the plot because they are known to influence tree mortality 201(Hülsmann et al., 2017; Vanoni, Cailleret, Hülsmann, Bugmann, \& Bigler, 2019). The number of 202years between surveys (yearsbetweensurvey) was also included in the model to account for mortality 203probability increases with elapsed time. We used BA, BAcon and BAhetero as proxies of total 204competition, intraspecific and interspecific competition (Kunstler et al., 2016).

\subsection{Statistical analyses}

\subsubsection{Selection of climatic and competition covariates in the mortality models}

208For each species, we ran 48 competing occurrence of mortality models. In each model we included 209the climatic marginality as a qualitative variable (i.e. the core, leading or trailing edge of each plot), 210the five stand covariates, and the minimum and mean SPEI indexes. We added all the possible 211combinations of one precipitation-related, one temperature-related and two competition variables. We 212included all interactions between marginality, the two SPEI indexes, the two competition-related 213variable and the two climate variables (Table S7).

$214 \mathrm{We}$ included both precipitation- and temperature-related variables to the models, in addition to 215marginality, because they could vary within the species margins and thus capture variations not 
216accounted by marginality variable. The collinearity between precipitation- and temperature-related 217variables and marginality were assessed using variation inflation factors (Supporting Information 218Table S8a,b).

\subsubsection{Statistical models of mortality}

221We used species-specific hurdle models to handle the zero-inflated distribution of tree mortality 222(Ruiz-Benito et al. 2017; Benito Garzón et al. 2018; Archambeau et al. 2020). Consequently, we 223analyzed separately the mortality occurrence between two census $(0 / 1=$ at least one tree is dead in the 224plot/ all trees are alive in the plot) and the intensity of mortality in plots where mortality occurs (the 225proportion of trees dead in the plot, Young et al., 2017). Firstly, mortality occurrence was analyzed 226with the binomial part of the hurdle model $\left(Y 1_{i}=1\right.$, table $\left.\mathrm{S} 3\right)$ where $p_{i}$ is the probability of 227occurrence of a mortality event in an individual plot $i$ during the census interval. We used a binomial 228GLMM with a logit link (BIN model) to estimate the parameters of the species-specific linear 229function $\eta_{1 i, s p}$ (Hülsmann et al., 2017):

$230 Y 1_{i}=1 \sim \operatorname{Bin}\left(n, p_{i}\right)$

$231 \operatorname{logit}\left(p_{i}\right)=\eta_{1 i, s p}$

232Secondly, we analyzed the intensity of mortality as the annual rate of mortality in plots where at least 233one tree was recorded as dead $\left(Y 2_{i}\right.$, Table S3) with zero truncated negative binomial mixed-effect 234models in the second part of the hurdle model (NB model), $Y 2_{i}$ where $\mu_{i}$ is the mean number of 235mortality events per year per hectare and $k$ is the inverse of the dispersion $\left(Y 2_{i} \sim N B\left(\mu_{i}, k\right)\right)$. We used 236NB models with a $\log$ link to estimate the parameters of the species-specific linear function $\eta_{2 i, s p}$ :

$237 Y 2_{i} \sim N B\left(\mu_{i}, k\right)$

$238 \log \left(\mu_{i}\right)=\eta_{2 i}$

240 Functions $\eta_{1 i, s p}$ and $\eta_{2 i, s p}$ take the same general form: 
$242 \eta_{i, s p}=\alpha_{0}+\sum_{h=1}^{16} \beta_{h} x_{h i, s p}+\sum_{n=1}^{21} \gamma_{n} x_{, s p} Z_{, s p}+\alpha_{c o u n t r y, s p}+\varepsilon_{i, s p}+b_{s p}$

243Where $\alpha_{0}$ is an intercept term, $\alpha_{\text {country,sp }}$ is the random country intercept to account for sampling

244differences between each NFI and follows a Gaussian distribution $\alpha_{\text {country,sp }} \sim N\left(0, \sigma_{\alpha_{\text {countrysp }}}^{2}\right) ; \varepsilon_{i, s p}$ is the

245residual error following a Gaussian distribution $\left(\varepsilon_{i, s p} \sim N\left(0, \sigma_{\varepsilon}^{2}\right)\right.$

$246) ; b_{s p}$ is an autocorrelation spatial effect that follows a Matérn distribution $\left(b_{s p} \sim\right.$ Maté $r n\left(v_{s p}, \rho_{s p}\right)$

247, where $v_{s p}$ is the smoothness and $\rho_{s p}$ the shape, Supporting Information Figure S3). $\beta_{h}$ is the regression

248coefficient for the $h$ th of 16 fixed effect predictors $x_{s p}$ (including 5 stand covariates, 2 climatic 249variables and their respective quadratic effect, 2 drought-related (SPEI) variables and their respective 250quadratic effect, 2 competition variables and marginality, see details below and in Supporting 251Information Tables S4, S6 and S7) and $\gamma_{n}$ the regression coefficient of the $n^{\text {th }}$ interaction between 252fixed effect predictors $X_{s p}$ and $z_{s p}$ (including all interactions between climatic variables, drought253related variables, competition variables and marginality).

254

$255 \alpha_{\text {country,sp }} \sim N\left(0, \sigma_{\alpha_{\text {countrysp }}}^{2}\right)$

$256 \varepsilon_{i, s p} \sim N\left(0, \sigma_{\varepsilon}^{2}\right)$

$258 b_{s p} \sim$ Maté $r n\left(v_{s p}, \rho_{s p}\right)$

\subsubsection{Model selection}

261To select the most parsimonious model, we applied the following procedure for each species:

262(1) We calculated the Variance Inflation Factor (VIF) for all 48 possible combinations of variables 263and removed combinations with VIF > 10 (Dormann et al., 2013; Table S8a,b); (2) We ran BIN 264models including each remaining combinations of variables and selected the combination with the 
265best predictive ability using the AIC (AIC < 2) and the log H-likelihood (largest values; Lee \& Nelder, 2662018); (3) We fitted an NB model including the same variables as those in the BIN model with the 267best predictive ability. (4) We used a stepwise approach for both the BIN and NB models (i.e. we 268removed the least significant variable to fit a new model) to obtain the most parsimonious models.

269All models were fitted with the SpaMM package (Rousset, Ferdy \& Courtiol, 2016; Table S6) under 270the R version 3.6.1.

271

\subsubsection{Model validation}

273The goodness-of-fit was evaluated with the area under the curve (AUC) for BIN models (Hurst, 274Allen, Coomes, \& Duncan, 2011) and with cross-validation for the NB models (models were fitted on $27566 \%$ of the data while the remaining $33 \%$ were used to validate the predictions, Table 1 ).

276The percentage of the variance explained by BIN and NB models was estimated by the marginal and 277conditional R-squared including fixed-effect and fixed plus random effects, respectively (Nakagawa 278\& Schielzeth, 2013). The proportion of change in explained variance between full and null model 279(PCV) indicates the variance retained by the selected model. All these metrics were calculated from 280the SPAMM objects using a personal script adapted from the piecewise Package (Lefcheck, 2016) 281according to Nakagawa methodology (Nakagawa \& Schielzeth, 2013, Nakagawa, Johnson \& 282Schielzeth, 2017).

283

\subsubsection{Comparison of spatial predictions and climatic marginality}

285We used the selected models to predict mortality occurrence and intensity across the range of NFI 286plots. To visually inspect the differences in the climatically marginal populations, we split the 287predicted values into three groups based on the quartiles, to indicate high, medium and low levels of 288mortality (Figure 3 and Supporting Information Tables S9, S10).

289To statistically test for heterogeneity in the distribution of the predicted probability among the three 290areas (core, leading edge and trailing edge), we compared the predicted distribution (Figure 3) against 
291the expected distribution under the assumption of no spatial structure in mortality occurrence (null 292hypothesis) with a $\chi$-square test. Under the null hypothesis, we expected the distribution to be 293uniformly distributed within the three areas (25\% of the values in each quartile) (Supporting 294Information Figure S4a). P-values $<0.05$ indicate that predicted mortality was different than expected 295under the null hypothesis. The same approach was used to test for patterns across the three areas in 296predicted mortality intensity (Supporting Information Figure S4b).

\section{RESULTS}

\subsection{Climatic marginality across species ranges}

300The variables that contributed the most in defining the core, trailing and leading areas were the annual 301evapotranspiration for 10 out of the 20 species, the maximum temperature of the warmest month for 302 four species and annual precipitation for four species (Table S5). Marginal areas (leading and trailing 303edges) were therefore areas exhibiting the highest or the lowest values for these climatic variables.

304We observed that our climatic marginality did not systematically match with the commonly used 305geographic marginality (northern part of species distribution corresponding to the geographical 306leading edge, and southern part to the geographical trailing edge), particularly in the mountainous 307areas which were included in the climatic leading edge for most species although they were mostly 308located in the central part of the range (geographical core) (Figure S2).

\subsection{Underlying drivers of occurrence and intensity of tree mortality}

312Overall, the occurrence of mortality was mostly located at the trailing edge and related to drought 313whereas the intensity of mortality was related to multiple drivers at the trailing edge and to the 314warmest temperature at the leading edge. Bigger trees (likely to be older trees) showed higher 315occurrence of mortality than smaller ones whereas intensity of mortality was similar across sizes (and 316therefore ages). 
318The variance explained by BIN models ranged from 6\% for Acer pseudoacacia to 46\% for Pinus 319pinaster and the AUC ranged from 0.769 for Quercus ilex to 0.850 for Acer pseudoplatanus (Table 3201). The variance explained by NB models ranged from $13 \%$ for Castanea sativa to $48 \%$ for Fraxinus 321excelsior and the cross-validation scores ranged from 0.256 for Quercus pyrenaica to 0.735 for 322Betula pendula. Accounting for spatial autocorrelation (SAC) in the models improved the capacity of 323generalization of the three models (i.e. from $25.61 \%$ to $57.54 \%$ for Quercus pyrenaica, Table 1).

325Competition-related variables (stand basal area of the species and stand basal areas of the other 326species at the plot) were the most frequently significant variables in BIN and NB models (significant 327in 13 out of 20 species for interspecific competition and 10 species for intraspecific competition, see 328estimated coefficients and their standard error in Supporting Information Table S11a,b and frequency 329in Table S12a,b). Precipitation, temperature and SPEI variables were retained in BIN models for 16, 33011 and 12 species respectively and in NB models for 11, 8 and 9 species (estimated coefficients and 331their standard error of the associated coefficient in Table S11a,b and frequency in Table S12a,b).

333Climatic marginality was significant in the BIN model in 5 species in the trailing edge and in 7 334species in the leading edge; and it was also significant in NB models in 3 species in the trailing edge 335and in 7 species in the leading edge (magnitude and standard error of the associated coefficient are 336shown in Table S11a,b and frequency in Table S12a,b).

338The average age of the plot (meanDBH) was significant in explaining both occurrence and intensity 339of mortality (positive association in 14 species and 11 species respectively) meaning that larger (and 340therefore older) trees were more affected by mortality. Average growth rate of the species of the plot 341(meanBAIj) was also significant in both models (negative associations in 18 species for BIN models 342and 7 in NB models) meaning that older plots (with the lowest average growth) are more likely to 
343experience mortality. Tree density (treenumber) was positively associated in both models (14 and 12

344species respectively for BIN and NB models). The number of years between surveys

345(yearsbetweensurvey) was also significant in explaining both the mortality occurrence probability

346between two census ( 6 species, BIN model) and the intensity of mortality ( 15 species, NB model)

347(Magnitude and standard error of the associated coefficient in Table S11a,b and frequency in Table 348 S12a,b)

349

350Interactions between marginality and SPEI variables were the most frequent in BIN models (17 351significant interactions, 9 at the trailing edge and 7 at the leading edge) whereas the interaction 352between climatic marginality and temperature-related variables was the most frequent in NB models 353(12 significant interactions, 3 at the trailing edge and 9 at the leading edge) (Supporting Information 354Table S11c,d). When drought conditions in the studied period were higher than in the reference 355period (lower values of mean SPEI), predicted tree mortality occurrence probability (BIN models) 356was higher in marginal than core areas, particularly at the trailing edge (for both temperate and 357Mediterranean species Abies alba, Picea abies, Pinus sylvestris, Castanea sativa Pinus pinea and 358Pinus nigra, Figure 1a-f). Under drier conditions than those experienced in the reference period (i.e. 359negative SPEI values), the highest probability of mortality was found in the core area for some 360temperate (Populus tremula, Quercus robur, Betula pendula (Supporting Information Figure S5a-c) 361and Mediterranean species (Pinus halepensis and Quercus pyrenaica (Supporting Information Figure 362S5d and Table S12c).

364In addition to drought, a few species also showed the highest tree mortality probability during the 365time between surveys at the climatic margins when precipitation were low or when temperatures were 366high. This was the case for the temperate species Fagus sylvatica and Fraxinus excelsior (Supporting 367Information Figure S6a and Table S12c) and the Mediterranean species Pinus pinaster and Quercus 368suber (Supporting Information Figure S6b-c). 
370The intensity of mortality (NB models) for the temperate species A.alba, B.pendula, F.sylvatica and 371P.abies was generally higher in the trailing edge than in the core but not always associated with low 372SPEI. It was associated with various variables as competition, lower SPEI, warmer temperatures or 373lower precipitation than in the core, depending on the species (Figure 2a-c and Supporting 374Information Figure S7a). In addition, a strong effect of high temperatures was observed in leading 375edge areas. Under high temperatures, both temperate (F.excelsior, Quercus petraea and Q.robur, 376Figure 2d-f) and Mediterranean species (Quercus ilex, P.halepensis, P.nigra and P.pinea; Supporting 377Information Figure S7b-c and Table S12d) showed more intense predicted mortality at the leading 378edge than in the core areas. Also, P.tremula populations are more likely to show high intensity of 379mortality at the core of its distribution when drought in the studied period was higher than in the 380reference period (lower values of mean SPEI) (Table S12d).

\subsection{Spatial patterns of occurrence and intensity of mortality across tree species ranges}

383The predicted probability of mortality occurrence (BIN models) was the highest in the trailing edge 384part of the range for eight temperate (Alnus glutinosa, Betula pendula, Picea abies, Pinus .sylvestris, 385Populus tremula, Fagus sylvatica, Quercus robur, Q. petraea) and three Mediterranean species 386(Quercus ilex, Q.pyrenaica, Castanea sativa) (Figure 3 and S4a). None of the species had a 387significantly higher probability of mortality occurrence in the core than in the margins, while two 388temperate species (P.abies and P.sylvestris) had lower probability of occurrence of mortality in the 389core than expected under the assumption of uniformity across the species range (Figure 3 and S4a). 390Four temperate species (Alnus glutinosa, Pinus sylvetris, Populus nigra, Quercus robur) and four 391Mediterranean species (Castanea sativa, Pinus nigra, P. pinea and Quercus ilex) had a lower 392probability of occurrence of mortality in the leading edge part of their range than the core (Figure 3 393and S4a). We did not find any spatial patterns in the intensity of mortality (NB models) in temperate 394species. However, the highest predicted intensity of mortality was at the leading edge part of the 
395species range for 6 Mediterranean species (P.halepensis, P.nigra, P.pinaster, P.pinea, Q.pyreneica, 396Q.suber) (Figure 3 and S4b)

397

3980nly six species showed similarities between the occurrence and intensity of predicted mortality 399(Figure 3): Castanea sativa, Quercus robur and Quercus ilex showed the lowest values of both types 400of predicted mortality at their leading edge whereas Acer pseudoplatanus displayed the lowest values 401at the trailing edge; the predicted intensity and occurrence of mortality predictions for Quercus ilex 402showed the highest values at the trailing edge. Picea abies showed the lowest predictions of 403occurrence and intensity of mortality in the core of the distribution and Pinus pinaster predicted 404mortality of both types was highest at the leading edge.

405

406

407

\section{DISCUSSION}

\subsection{Drivers of occurrence and intensity of tree mortality across European tree ranges}

411Our results are in agreement with previous studies showing that the combination of drought and 412competition exacerbate the probability of mortality occurrence (Ruiz-Benito et al. 2013, Young, 4132017) (Tables S11a, S12a), while intense events are driven by multiple factors (including drought and 414competition) (Anderegg et al., 2015; Jump et al. 2017; Seidl et al., 2017; Wood, Knapp, Muzika, 415Stambaugh, \& Gu, 2018). As expected, the most intense mortality events were associated with low 416precipitation and high temperatures, the latter only for half of the species (Tables S11b, S12b). This 417may be explained by the synergic effects of low precipitation and warm temperatures with insect 418outbreaks (not included in our models) that may end into die-off events (Anderegg et al., 2015; Kurz 419et al., 2008; McDowell et al., 2011; Wood et al., 2018). 
421The importance of drought for the occurrence of mortality was higher in marginal populations that 422experienced drier than average conditions during the study period, suggesting that these populations 423are the most vulnerable to climate warming (Figure 1a-f and S6a-c). Although in exceptional cases, 424the highest level of relative drought was more detrimental for core than marginal populations (Figure 425S5a-d). Interestingly, high temperatures at the leading edge were correlated with the most intense 426events of mortality for many species, whereas the combination of drought and climatic marginality 427was less important in mortality intensity than occurrence (Figure 2d-f and S7b-c). Other studies have 428already observed an increase in background mortality in mild climates and at the northern margin of 429species ranges associated with warm temperature (Ruiz Benito et al. 2013; Neuman et al. 2017). The 430less important role of drought in explaining intensity of mortality could be explained by the time lag 431between stressful conditions and mortality responses, making it complicated to detect such small-time 432scale effects (Jump et al., 2017). We found a larger effect of competition on intensity of mortality at 433the trailing edge than at the core in temperate species (Figure 2a-c and S7a), which could be 434explained by the presence of more competitive and less prone to hydraulic risk Mediterranean species 435reaching their leading edge (Benito Garzón 2013, 2018).

\subsection{Placing tree mortality at large geographical gradients}

438Mortality is an important component of demography and as such, its geographical patterns can be 439used to describe demographic and ecological differences of the core versus the peripheral populations 440(Purves, 2009; Pironon et al., 2017). We showed that the occurrence of mortality is greater in 441climatically marginal regions than at the climatic core of the species ranges. Furthermore, plots 442containing largest trees (higher DBH classes) and trees with the lowest growth rate (lower meanBAIj) 443were often associated with high mortality occurrence probability, suggesting that oldest trees are 444more likely to die (Vanoni et al., 2019; Hülsmann et al., 2017; Cailleret et al., 2017) (Table S11a). 445The predicted probability of mortality occurrence was the highest in the trailing edge for most 446temperate species and the lowest in the leading edge for half of the Mediterranean species (Figure 3 
447and S4a). This suggest that the Mediterranean-temperate ecotone is a hotspot of forest composition 448changes, as previously suggested on the European gradients of water availability (Ruiz-Benito et al. 4492017). Furthermore, in Mediterranean species, mortality occurrence was more likely to be higher in 450the trailing edge than in the core under intense drought (Figure 1d-f), suggesting that the southern part 451of the species ranges can be delimited by drought-induced mortality (Benito-Garzón et al., 2013; 452Benito Garzón et al., 2018; Gárate-Escamilla, Hampe, Vizcaíno-Palomar, Robson, \& Benito Garzón, 4532019; Kunstler et al., 2016). This result also highlights that drought increases in southern Europe are 454boosting background mortality in the last years (Benito Garzón et al., 2018; Carnicer et al., 2011; 455Druckenbrod et al., 2019; Neumann et al., 2017; Ruiz-Benito et al., 2013).

457Conversely, the most intense events of mortality are evenly distributed in the European extent studied 458(Allen et al., 2015; Allen et al., 2010; Jump et al., 2009; Jump et al., 2017) and they are not related 459with old trees (DBH classes) or slow growth (meanBAIj) (Table S11b), suggesting they can affect all 460class of trees age and size as expected for die-off events. As such, die-off mortality can be affected by 461other important factors such as large competition (Young et al. 2017), pest emergence, fires etc. and 462result in unexpected demographic patterns. (Jump et al., 2017).

463

\subsection{Limitations and perspectives}

465Although recently managed forests have been removed from our analysis according to management 466information in forest inventories (Ruiz-Benito et al. 2020), further legacy effects for which no 467information is available could affect mortality (Clark, Bell, Hersh, \& Nichols, 2011; Csilléry et al., 4682013, Young 2017). In addition, disturbance magnitude and duration could have contrasting lag 469effects and the differences in the time lag between surveys in our data can result in large uncertainties 470(Druckenbrod et al., 2019). 
472Our findings provide a new perspective to study tree mortality in forests from NFI data as both

473demographic and stochastic processes are exacerbated to some extent by drought stress but also by an

474interaction of climatic drivers that change across species ranges.

475

\section{Acknowledgements}

477This study was funded by the "Investments for the Future” program IdEx Bordeaux (ANR-10-IDEX47803-02) and the ATHENEE project (Nouvelle-Aquitaine Région). We thank the FunDivEUROPE 479project (European Union Seventh Framework Programme (ㅍ7/2007-2013) under grant agreement no 480265171) for the previous harmonization of the National Forest Inventory data used in this study. 481MAZ and PRB were supported by grant DARE; RTI2018-096884-B-C32 (MICINN, Spain).

482

\section{REFERENCES}

484

485Allen, C. D., Breshears, D. D., \& McDowell, N. G. (2015). On underestimation of global $486 \quad$ vulnerability to tree mortality and forest die-off from hotter drought in the Anthropocene. 487 Ecosphere, 6(8), 1-55. https://doi.org/10.1890/ES15-00203.1

488Allen, C. D., Macalady, A. K., Chenchouni, H., Bachelet, D., McDowell, N., Vennetier, M., ... Cobb, 489 N. (2010). A global overview of drought and heat-induced tree mortality reveals emerging 490 climate change risks for forests. Forest Ecology and Management, 259(4), 660-684. 491 https://doi.org/10.1016/j.foreco.2009.09.001

492Anderegg, W. R., Hicke, J. A., Fisher, R. A., Allen, C. D., Aukema, J., Bentz, B., ... \& Pan, Y. 493 (2015). Tree mortality from drought, insects, and their interactions in a changing climate. New 494 Phytologist, 208(3), 674-683. https://doi.org/10.1111/nph.13477

495Archambeau, J., Ruiz-Benito, P., Ratcliffe, S., Fréjaville, T., Changenet, A., Castañeda, J. M. M., ... 496 \& Garzón, M. B. (2020). Similar patterns of background mortality across Europe are mostly 497 driven by drought in European beech and a combination of drought and competition in Scots 498 pine. Agricultural and Forest 107772. 499 https://doi.org/10.1016/j.agrformet.2019.107772

500Baeten, L., Verheyen, K., Wirth, C., Bruelheide, H., Bussotti, F., Finér, L., ... \& Ampoorter, E. 501 (2013). A novel comparative research platform designed to determine the functional significance 502 of tree species diversity in European forests. Perspectives in Plant Ecology, Evolution and 503 Systematics, 15(5), 281-291. https://doi.org/10.1016/j.ppees.2013.07.002

504Benito-Garzón, M., Ruiz-Benito, P., \& Zavala, M. A. (2013). Interspecific differences in tree growth 505 and mortality responses to environmental drivers determine potential species distributional limits 
506 in Iberian forests. Global Ecology and Biogeography, 22(10), 1141-1151.

507 https://doi.org/10.1111/geb.12075

508Benito-Garzón, M., Leadley, P. W., \& Fernández-Manjarrés, J. F. (2014). Assessing global biome 509 exposure to climate change through the $\mathrm{H}$ olocene-A nthropocene transition. Global Ecology 510 and Biogeography, 23(2), 235-244. https://doi.org/10.1111/geb.12097

511Benito Garzón, M., González Muñoz, N., Wigneron, J. P., Moisy, C., Fernández-Manjarrés, J., \& 512 Delzon, S. (2018). The legacy of water deficit on populations having experienced negative 513 hydraulic safety margin. Global Ecology and Biogeography, 27(3), 346-356. 514 https://doi.org/10.1111/geb.12701

515Breshears, D. D., Cobb, N. S., Rich, P. M., Price, K. P., Allen, C. D., Balice, R. G., ... Meyer, C. W. 516 (2005). Regional vegetation die-off in response to global-change-type drought. Proceedings of 517 the National Academy of Sciences, 102(42), 15144-15148. 518 https://doi.org/10.1073/pnas.0505734102

519Bugmann, H., Seidl, R., Hartig, F., Bohn, F., Brůna, J., Cailleret, M., ... Reyer, C. P. O. (2019). Tree 520 mortality submodels drive simulated long-term forest dynamics: assessing 15 models from the 521 stand to global scale. Ecosphere, 10(2). https://doi.org/10.1002/ecs2.2616

522Cailleret, M., Jansen, S., Robert, E. M. R., Desoto, L., Aakala, T., Antos, J. A., ... Martínez-Vilalta, J. 523 (2017). A synthesis of radial growth patterns preceding tree mortality. Global Change Biology, 524 23(4), 1675-1690. https://doi.org/10.1111/gcb.13535

525Carnicer, J., Coll, M., Ninyerola, M., Pons, X., Sanchez, G., \& Penuelas, J. (2011). Widespread 526 crown condition decline, food web disruption, and amplified tree mortality with increased 527 climate change-type drought. Proceedings of the National Academy of Sciences, 108(4), 1474528 1478. https://doi.org/10.1073/pnas.1010070108

529Caudullo, G., Welk, E., \& San-Miguel-Ayanz, J. (2017). Chorological maps for the main European 530 woody species. Data in brief, 12, 662-666. https://doi.org/10.1016/j.dib.2017.05.007

531Clark, J. S., Bell, D. M., Hersh, M. H., \& Nichols, L. (2011). Climate change vulnerability of forest 532 biodiversity: Climate and competition tracking of demographic rates. Global Change Biology, 533 17(5), 1834-1849. https://doi.org/10.1111/j.1365-2486.2010.02380.x

534Csilléry, K., Seignobosc, M., Lafond, V., Kunstler, G., \& Courbaud, B. (2013). Estimating long-term 535 tree mortality rate time series by combining data from periodic inventories and harvest reports in 536 a Bayesian state-space model. Forest Ecology and Management, 292, 64-74. 537 https://doi.org/10.1016/j.foreco.2012.12.022

538Dormann, C. F., Elith, J., Bacher, S., Buchmann, C., Carl, G., Carré, G., ... \& Münkemüller, T. 539 (2013). Collinearity: a review of methods to deal with it and a simulation study evaluating their 540 performance. Ecography, 36(1), 27-46. https://doi.org/10.1111/j.1600-0587.2012.07348.x

541Druckenbrod, D. L., Martin-Benito, D., Orwig, D. A., Pederson, N., Poulter, B., Renwick, K. M., \& 542 Shugart, H. H. (2019). Redefining temperate forest responses to climate and disturbance in the 543 eastern United States: New insights at the mesoscale. Global Ecology and Biogeography, 28(5), 544 557-575. https://doi.org/10.1111/geb.12876 
545Franklin, J. F., Shugart, H. H., \& Harmon, M. E. (1987). Tree Death as an Ecological Process. 546 BioScience, 37(8), 550-556. https://doi.org/10.2307/1310665

547Fréjaville, T., \& Benito Garzón, M. (2018). The EuMedClim database: Yearly climate data (1901548 2014) of $1 \mathrm{~km}$ resolution grids for Europe and the Mediterranean basin. Frontiers in Ecology and 549 Evolution, 6, 31._https://doi.org/10.3389/fevo.2018.00031

550Gárate-Escamilla, H., Hampe, A., Vizcaíno-Palomar, N., Robson, T. M., \& Benito Garzón, M. 551 (2019). Range-wide variation in local adaptation and phenotypic plasticity of fitness-related 552 traits in Fagus sylvatica and their implications under climate change. Global Ecology and 553 Biogeography, (April), 1336-1350. https://doi.org/10.1111/geb.12936

554Greenwood, S., Ruiz-Benito, P., Martínez-Vilalta, J., Lloret, F., Kitzberger, T., Allen, C. D., ... \& 555 Kraft, N. J. (2017). Tree mortality across biomes is promoted by drought intensity, lower wood 556 density and higher specific leaf area. Ecology Letters, 20(4), 539-553. 557 https://doi.org/10.1111/ele.12748

558Hartmann, H., Schuldt, B., Sanders, T. G. M., Macinnis-Ng, C., Boehmer, H. J., Allen, C. D., ... 559 Anderegg, W. R. L. (2018). Monitoring global tree mortality patterns and trends. Report from 560 the VW symposium 'Crossing scales and disciplines to identify global trends of tree mortality as 561 indicators of forest health.' New Phytologist, 217(3), 984-987. 562 https://doi.org/10.1111/nph.14988

563Hülsmann, L., Bugmann, H., \& Brang, P. (2017). How to predict tree death from inventory data564 lessons from a systematic assessment of European tree mortality models. Canadian Journal of 565 Forest Research, 47(7), 890-900. https://doi.org/10.1139/cjfr-2016-0224

566Hurst, J. M., Allen, R. B., Coomes, D. A., \& Duncan, R. P. (2011). Size-specific tree mortality varies 567 with neighbourhood crowding and disturbance in a montane Nothofagus forest. PloS one, 6(10). 568 https://doi.org/10.1371/journal.pone.0026670

569IPCC. (2014). Climate change 2014. Synthesis report. Versión inglés. Climate Change 2014: 570 Synthesis Report. Contribution of Working Groups I, II and III to the Fifth Assessment Report 571 of the Intergovernmental Panel on Climate Change. https://doi.org/10.1017/CBO9781107415324 572Jombart, T. (2008). adegenet: a R package for the multivariate analysis of genetic 573 markers. Bioinformatics, 24(11), 1403-1405. https://doi.org/10.1093/bioinformatics/btn129

574Jump, A. S., Mátyás, C., \& Peñuelas, J. (2009). The altitude-for-latitude disparity in the range 575 retractions of woody species. Trends in ecology \& evolution, 24(12), 694-701. 576 https://doi.org/10.1016/j.tree.2009.06.007

577Jump, A. S., Ruiz-Benito, P., Greenwood, S., Allen, C. D., Kitzberger, T., Fensham, R., ... Lloret, F. 578 (2017). Structural overshoot of tree growth with climate variability and the global spectrum of 579 drought-induced forest dieback. Global Change Biology, 23(9), 3742-3757. $580 \quad$ https://doi.org/10.1111/gcb.13636

581Kunstler, G., Falster, D., Coomes, D. A., Hui, F., Kooyman, R. M., Laughlin, D. C., ... Westoby, M. 582 (2016). Plant functional traits have globally consistent effects on competition. Nature, 583 529(7585), 204-207. https://doi.org/10.1038/nature16476 
584Kurz, W. A., Dymond, C. C., Stinson, G., Rampley, G. J., Neilson, E. T., Carroll, A. L., ... Safranyik, 585 L. (2008). Mountain pine beetle and forest carbon feedback to climate change. Nature, 586 452(7190), 987-990. https://doi.org/10.1038/nature06777

587Lee, Y., Nelder, J. A., \& Pawitan, Y. (2018). Generalized linear models with random effects: unified 588 analysis via H-likelihood. Chapman and Hall/CRC.

589Lefcheck, J. S. (2016). piecewiseSEM: Piecewise structural equation modelling in $\mathrm{r}$ for ecology, 590 evolution, and systematics. Methods in Ecology and Evolution, 7(5), 573-579. 591 https://doi.org/10.1111/2041-210X.12512

592McDowell, N., Pockman, W. T., Allen, C. D., Breshears, D. D., Cobb, N., Kolb, T., ... \& Yepez, E. 593 A. (2008). Mechanisms of plant survival and mortality during drought: why do some plants 594 survive while others succumb to drought?. New phytologist, 178(4), 719-739. 595 https://doi.org/10.1016/j.biocon.2016.01.028

596McDowell, N., Allen, C. D., Anderson-Teixeira, K., Brando, P., Brienen, R., Chambers, J., ... \& 597 Espirito-Santo, F. (2018). Drivers and mechanisms of tree mortality in moist tropical 598 forests. New Phytologist, 219(3), 851-869. https://doi.org/10.1111/nph.15027

599McDowell, N. G., Beerling, D. J., Breshears, D. D., Fisher, R. A., Raffa, K. F., \& Stitt, M. (2011). 600 The interdependence of mechanisms underlying climate-driven vegetation mortality. Trends in 601 Ecology and Evolution, 26(10), 523-532. https://doi.org/10.1016/j.tree.2011.06.003

602Mueller-Dombois, D. (1987). Natural dieback in forests. BioScience, 37(8), 575-583. 603 https://doi.org/10.2307/1310668

604Nakagawa, S., \& Schielzeth, H. (2013). A general and simple method for obtaining R2 from 605 generalized linear mixed-effects models. Methods in ecology and evolution, 4(2), 133-142. 606 https://doi.org/10.1111/j.2041-210x.2012.00261.x

607Nakagawa, S., Johnson, P. C., \& Schielzeth, H. (2017). The coefficient of determination R 2 and 608 intra-class correlation coefficient from generalized linear mixed-effects models revisited and 609 expanded. Journal of the Royal Society Interface, 14(134), 20170213. 610 https://doi.org/10.1098/rsif.2017.0213

611Neumann, M., Mues, V., Moreno, A., Hasenauer, H., \& Seidl, R. (2017). Climate variability drives 612 recent tree mortality in Europe. Global Change Biology, 23(11), 4788-4797. 613 https://doi.org/10.1111/gcb.13724

614Pironon, S., Papuga, G., Villellas, J., Angert, A. L., García, M. B., \& Thompson, J. D. (2017). 615 Geographic variation in genetic and demographic performance: new insights from an old 616 biogeographical paradigm. Biological Reviews, 92(4), 1877-1909. 617 https://doi.org/10.1111/brv.12313

618Purves, D. W. (2009). The demography of range boundaries versus range cores in eastern US tree 619 species. Proceedings of the Royal Society B: Biological Sciences, 276(1661), 1477-1484. 620 https://doi.org/10.1098/rspb.2008.1241

621Rousset, F., Ferdy, J. B., \& Courtiol, A. (2016). spaMM: Mixed models, particularly spatial 622 GLMMs. R package version, 1(2). 
623Ruiz-Benito, P., Lines, E. R., Gómez-Aparicio, L., Zavala, M. A., \& Coomes, D. A. (2013). Patterns 624 and Drivers of Tree Mortality in Iberian Forests: Climatic Effects Are Modified by Competition.

625 PLoS ONE, 8(2). https://doi.org/10.1371/journal.pone.0056843

626Ruiz-Benito, P., Ratcliffe, S., Jump, A. S., Gómez-Aparicio, L., Madrigal-Gonzalez, J., Wirth, C., ... 627 Zavala, M. A. (2017). Functional diversity underlies demographic responses to environmental 628 variation in European forests. Global Ecology and Biogeography, 26(2), 128-141. 629 https://doi.org/10.1111/geb.12515

630Ruiz-Benito, P., Vacchiano, G., Lines, E. R., Reyer, C. P., Ratcliffe, S., Morin, X., ... \& Palacios631 Orueta, A. (2020). Available and missing data to model impact of climate change on European 632 forests. Ecological Modelling, 416, 108870. https://doi.org/10.1016/j.ecolmodel.2019.108870

633Seidl, R., Thom, D., Kautz, M., Martin-Benito, D., Peltoniemi, M., Vacchiano, G., ... O Reyer, C. P. 634 (2017). Forest disturbances under climate change Europe PMC Funders Group. Nat Clim 635 Change, 7, 395-402. https://doi.org/10.1038/nclimate3303

636Vanoni, M., Cailleret, M., Hülsmann, L., Bugmann, H., \& Bigler, C. (2019). How do tree mortality 637 models from combined tree-ring and inventory data affect projections of forest succession? 638 Forest Ecology and Management, 433(November 2018), 606-617. 639 https://doi.org/10.1016/j.foreco.2018.11.042

640Vicente-Serrano, S. M., Beguería, S., \& López-Moreno, J. I. (2010). A multiscalar drought index 641 sensitive to global warming: the standardized precipitation evapotranspiration index. Journal of 642 climate, 23(7), 1696-1718. https://doi.org/10.1175/2009JCLI2909.1

643Wood, J. D., Knapp, B. O., Muzika, R. M., Stambaugh, M. C., \& Gu, L. (2018). The importance of 644 drought-pathogen interactions in driving oak mortality events in the Ozark Border 645 Region. Environmental Research $\quad$ Letters, 13(1), 015004. 646 https://doi.org/10.1088/1748-9326/aa94fa

647Young, D. J. N., Stevens, J. T., Earles, J. M., Moore, J., Ellis, A., Jirka, A. L., \& Latimer, A. M. 648 (2017). Long-term climate and competition explain forest mortality patterns under extreme 649 drought. Ecology Letters, 20(1), 78-86. https://doi.org/10.1111/ele.12711 
bioRxiv preprint doi: https://doi.org/10.1101/2020.10.30.362087; this version posted November 1, 2020. The copyright holder for this preprint (which was not certified by peer review) is the author/funder, who has granted bioRxiv a license to display the preprint in perpetuity. It is made available under aCC-BY-NC-ND 4.0 International license.

Figure 1: Effect of the interaction between drought (mean SPEI index) and marginality on predicted mortality occurrence per plot (expressed as a probability) across the core (black lines), trailing (red lines) and leading edge (blue lines) of three temperate species: a) Abies alba, b) Picea abies, c) Pinus sylvestris; and three Mediterranean - warm temperate species: d) Castanea sativa, e) Pinus pinea, f) Pinus nigra. Predictions within the ranges of the environmental gradients covered by the species are shown by solid colors and extrapolations outside the environmental gradients covered by the species are shown in transparent colors. For the case of Castanea sativa our data did not cover the leading edge of the species. T-values of the main effects interacting with marginality are reported.

a) ABIALB

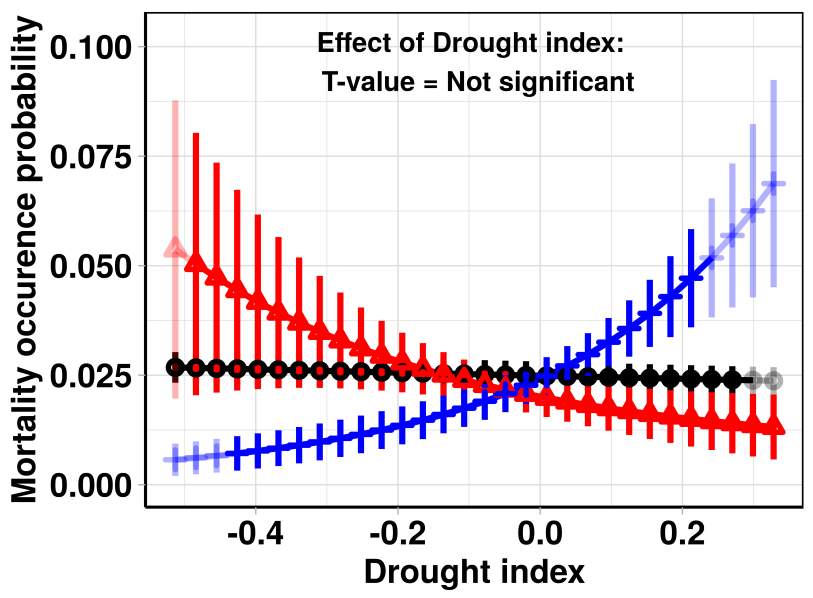

b) PICABI Marginality : Drought index

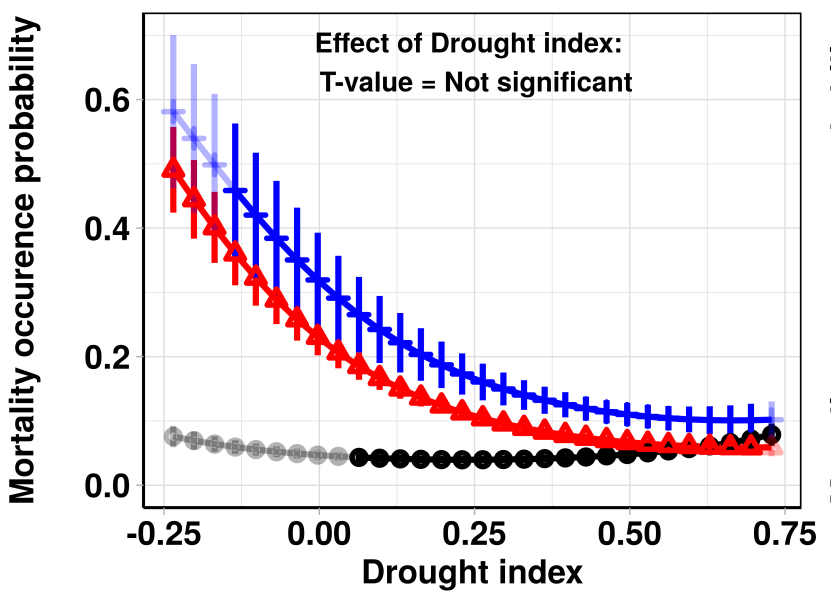

c) PINSYL Marginality : Drought index

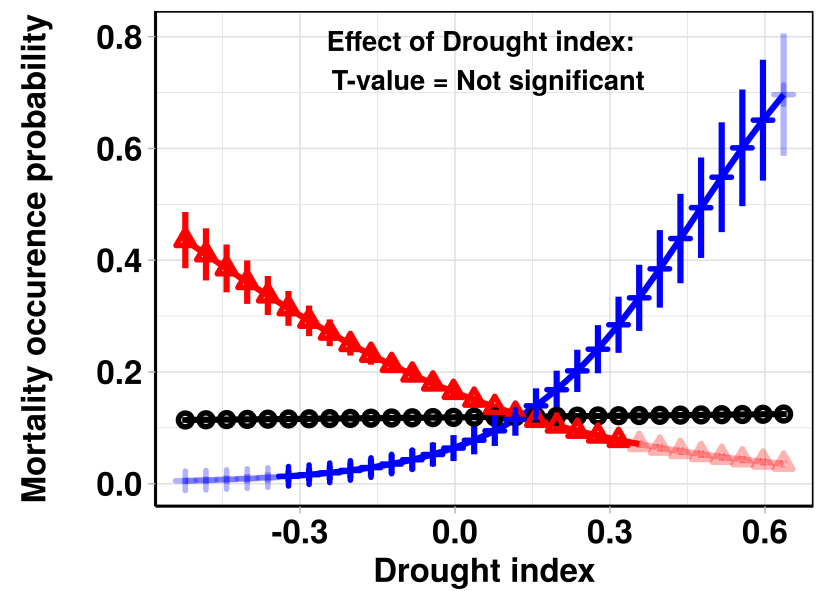

d) CASSAT Marginality : Drought index

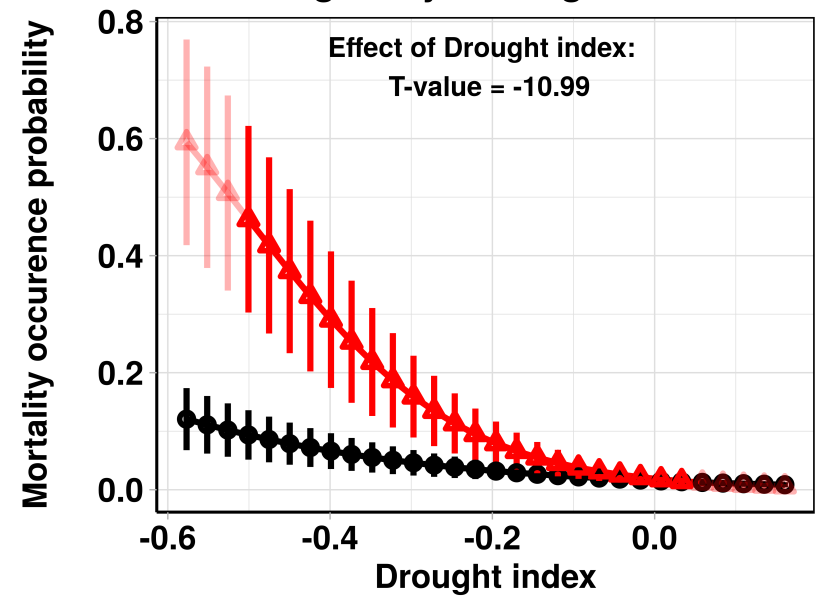

e) PINPIN Marginality : Drought index

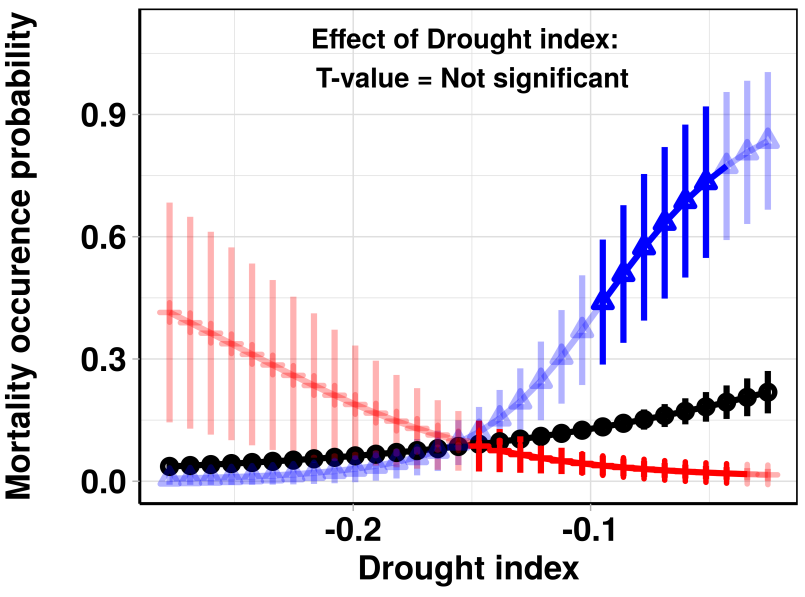

f) PINNIG Marginality : Drought index

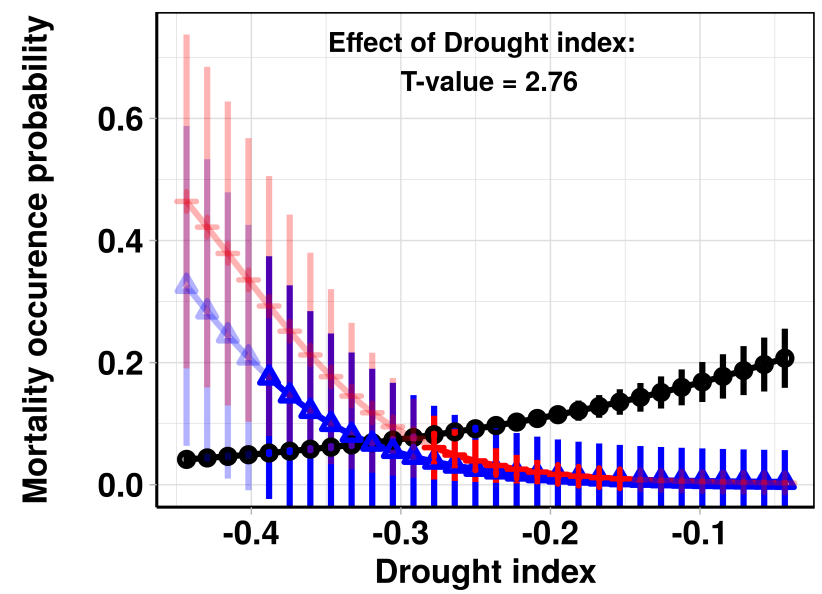

$\uparrow$ Core + Trailing Edge + Leading Edge 
bioRxiv preprint doi: https://doi.org/10.1101/2020.10.30.362087; this version posted November 1, 2020. The copyright holder for this preprint (which was not certified by peer review) is the author/funder, who has granted bioRxiv a license to display the preprint in perpetuity. It is made available under aCC-BY-NC-ND 4.0 International license.

Figure 2: Effect of the interaction between climatic variables on the predicted intensity of mortality across the core (black lines), trailing (red lines) and leading edge (blue lines) of six temperate species: a) Abies alba, b) Betula pendula, c) Fagus sylvatica, d) Fraxinus excelsior, e) Quercus petraea, f) Quercus robur), expressed as the proportion $(\%)$, by year and by plot. Predictions within the ranges of the environmental gradients covered by the species are shown by solid colors and extrapolations outside the environmental gradients covered by the species are shown in light colors. T-values of the main effects interacting with marginality are reported.

a) ABIALB

Marginality : Winter mean temperature

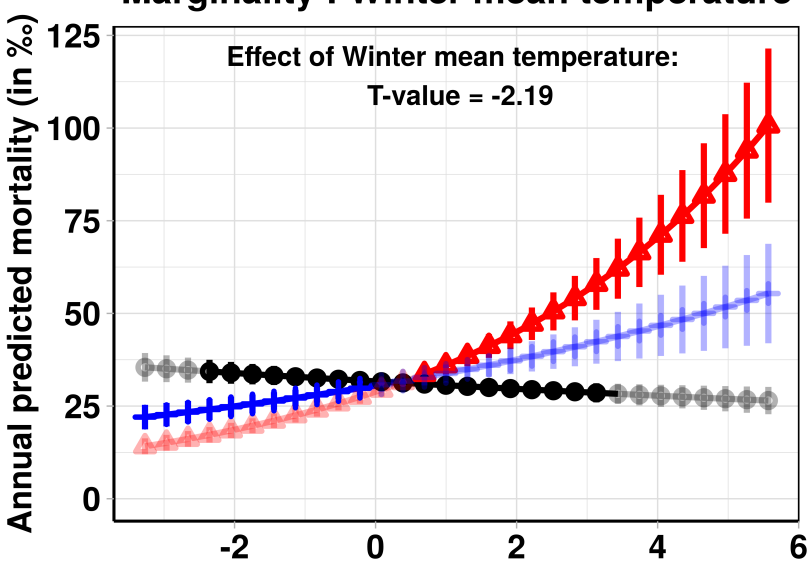

b) BETPEN

Winter mean temperature $\left({ }^{\circ} \mathrm{C}\right)$

Marginality : Drought index

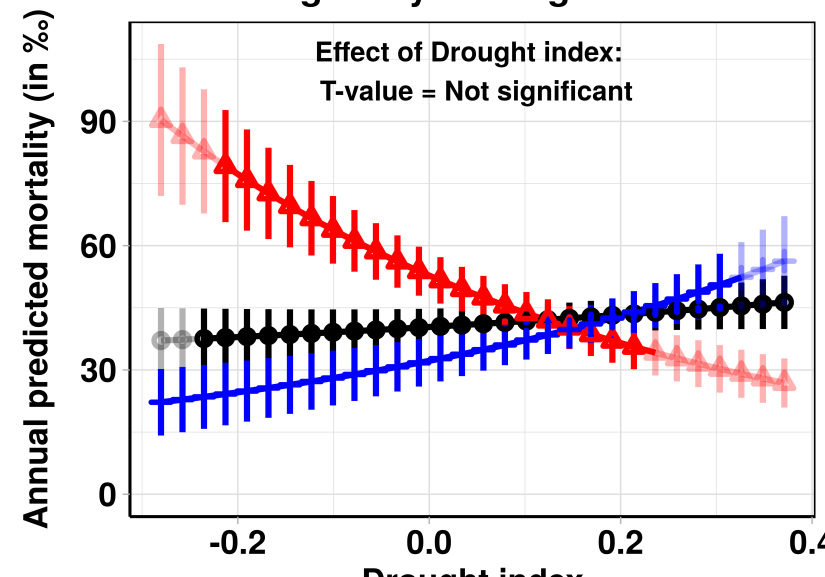

c) FAGSYL

Drought index

Marginality : Driest month precipitation

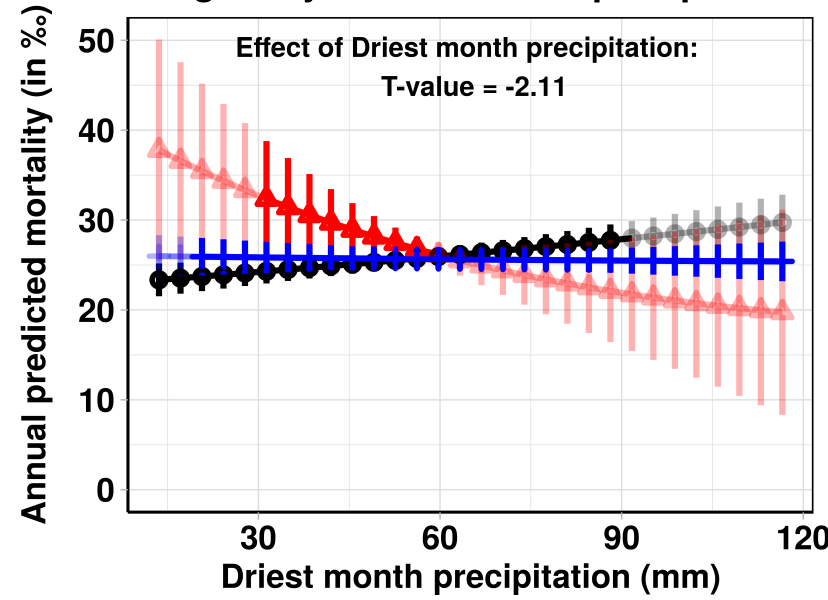

d) FRAEXC

Marginality : Warmest month max temperatu

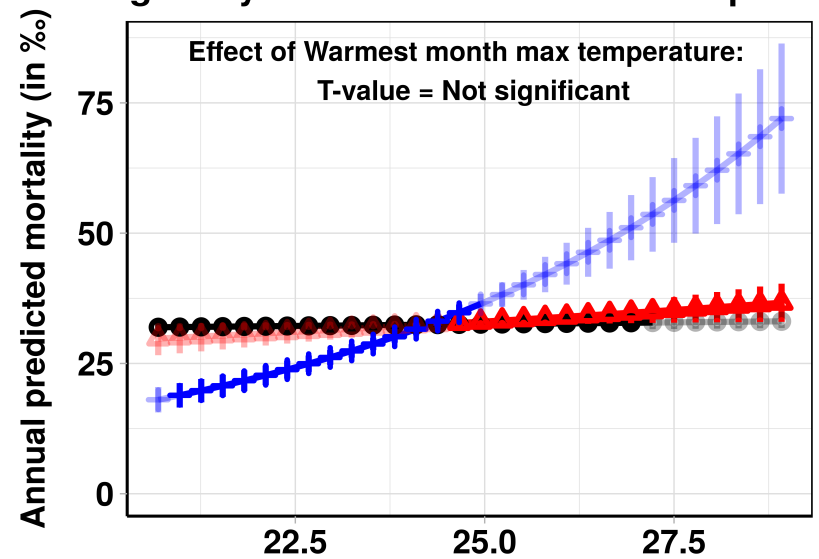

e) QUEPET

Marginality : Annual mean temperature

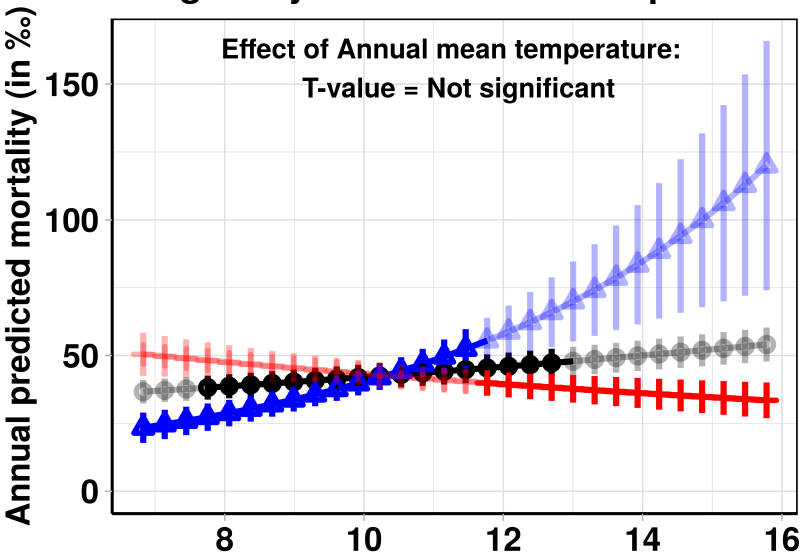

f) QUEROB

Annual mean temperature $\left({ }^{\circ} \mathrm{C}\right)$

Marginality : Warmest month max temperatu

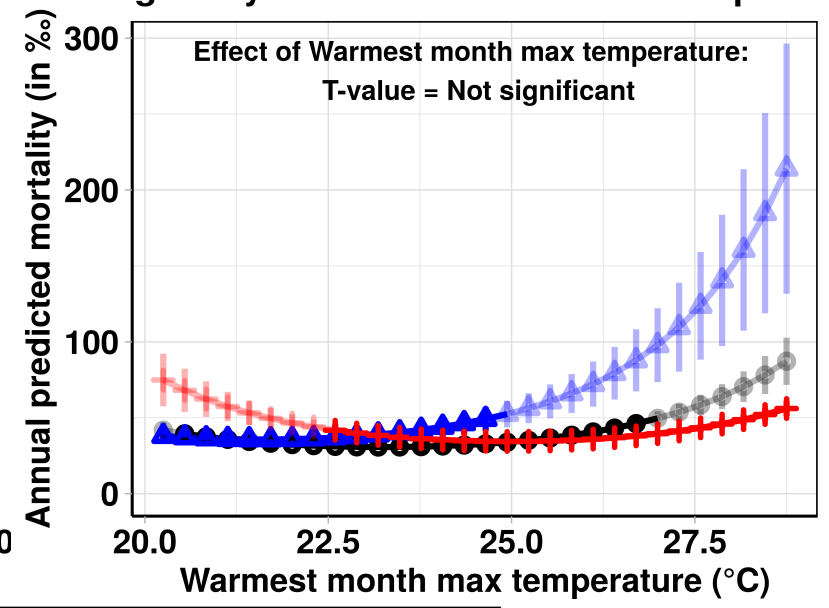


bioRxiv preprint doi: https://doi.org/10.1101/2020.10.30.362087; this version posted November $1,2020$. The copyright holder for this preprint (which was not certified by peer review) is the author/funder, who has granted bioRxiv a license to display the preprint in perpetuity. It is made available under aCC-BY-NC-ND 4.0 International license.

Table 1: Statistical evaluation of occurrence and intensity of mortality models, by species. Species: Name of the species. Code: Code used for each species Model: model type: Occurrence, intensity or intensity of mortality model including spatial autocorrelation (intensity + SAC - Spatial Autocorrelation -). R2M: Marginal r-squared. R2C: conditional r-squared. PCVObs: proportion change in variance between null model and fixed effect model (in \%). COG: capacity of generalization. AUC (Area Under the Curve) for mortality occurrence models and CV (Cross Validation score) for intensity of mortality models.

\begin{tabular}{|c|c|c|c|c|c|c|}
\hline Species & Code & Model & R2M & $\mathrm{R} 2 \mathrm{C}$ & PCVObs & $\begin{array}{c}\text { COG } \\
(\mathrm{AUC} / \mathrm{CV})\end{array}$ \\
\hline Abies alba Mill. & ABIALB & Occurrence & 0.13 & 0.42 & -1.98 & 0.82 \\
\hline Acer pseudoplatanus L. & ACEPSE & Occurrence & 0.06 & 0.2 & -9.25 & 0.85 \\
\hline Alnus glutinosa (L). Gaertn. & ALNGLU & Occurrence & 0.2 & 0.26 & -1.45 & 0.81 \\
\hline Betula pendula Roth. & BETPEN & Occurrence & 0.09 & 0.34 & -5.55 & 0.83 \\
\hline Castanea sativa Mill. & CASSAT & Occurrence & 0.21 & 0.56 & -1.18 & 0.82 \\
\hline Fagus sylvatica L. & FAGSYL & Occurrence & 0.11 & 0.12 & -3.55 & 0.82 \\
\hline Fraxinus excelsior L. & FRAEXC & Occurrence & 0.07 & 0.38 & -5.59 & 0.84 \\
\hline Picea abies (L.) H.Karst. & PICABI & Occurrence & 0.15 & 0.19 & -1.68 & 0.78 \\
\hline Pinus halepensis Mill. & PINHAL & Occurrence & 0.22 & 0.22 & -1.46 & 0.80 \\
\hline Pinus nigra J.F.Arnold. & PINNIG & Occurrence & 0.19 & 0.24 & -1.74 & 0.81 \\
\hline Pinus pinaster Aiton. & PINPINA & Occurrence & 0.46 & 0.46 & -0.52 & 0.85 \\
\hline Pinus pinea $\mathrm{L}$. & PINPIN & Occurrence & 0.24 & 0.24 & -1.2 & 0.81 \\
\hline Pinus sylvestris L. & PINSYL & Occurrence & 0.22 & 0.26 & -1.17 & 0.80 \\
\hline Populus nigra L. & POPNIG & Occurrence & 0.19 & 0.46 & -1.39 & 0.84 \\
\hline Populus tremula L. & POPTRE & Occurrence & 0.12 & 0.24 & -2.83 & 0.82 \\
\hline Quercus ilex L. & QUEILE & Occurrence & 0.12 & 0.37 & -2.98 & 0.77 \\
\hline Quercus petraea Liebl. & QUEPET & Occurrence & 0.13 & 0.36 & -2.63 & 0.83 \\
\hline Quercus pyrenaica Willd. & QUEPYR & Occurrence & 0.17 & 0.17 & -2.04 & 0.79 \\
\hline Quercus robur L. & QUEROB & Occurrence & 0.28 & 0.52 & -1.37 & 0.83 \\
\hline Quercus suber L. & QUESUB & Occurrence & 0.15 & 0.15 & -1.2 & 0.77 \\
\hline Abies alba Mill. & ABIALB & Intensity & 0.2 & 0.5 & 0.31 & 0.58 \\
\hline Acer pseudoplatanus L. & ACEPSE & Intensity & 0.21 & 0.92 & 0.7 & 0.51 \\
\hline Alnus glutinosa (L). Gaertn. & ALNGLU & Intensity & 0.39 & 0.44 & 0.4 & 0.53 \\
\hline Betula pendula Roth. & BETPEN & Intensity & 0.42 & 0.66 & 0.53 & 0.73 \\
\hline Betula pendula Roth. & BETPEN & Intensity + SAC & 0.42 & 0.71 & 0.6 & NA \\
\hline Castanea sativa Mill. & CASSAT & Intensity & 0.13 & 0.78 & 0.38 & 0.57 \\
\hline Fagus sylvatica L. & FAGSYL & Intensity & 0.23 & 0.46 & 0.25 & 0.37 \\
\hline Fraxinus excelsior L. & FRAEXC & Intensity & 0.46 & 0.46 & 0.52 & 0.64 \\
\hline Fraxinus excelsior L. & FRAEXC & Intensity + SAC & 0.48 & 0.52 & 0.51 & NA \\
\hline Picea abies (L.) H.Karst. & PICABI & Intensity & 0.22 & 0.41 & 0.33 & 0.57 \\
\hline
\end{tabular}


bioRxiv preprint doi: https://doi.org/10.1101/2020.10.30.362087; this version posted November 1,2020 . The copyright holder for this preprint (which was not certified by peer review) is the author/funder, who has granted bioRxiv a license to display the preprint in perpetuity. It is made available under aCC-BY-NC-ND 4.0 International license.

\begin{tabular}{|c|c|c|c|c|c|c|}
\hline Pinus halepensis Mill. & PINHAL & Intensity & 0.26 & 0.26 & 0.33 & 0.60 \\
\hline Pinus nigra J.F.Arnold. & PINNIG & Intensity & 0.2 & 0.41 & 0.32 & 0.32 \\
\hline Pinus pinaster Aiton. & PINPINA & Intensity & 0.29 & 0.29 & 0.38 & 0.62 \\
\hline Pinus pinea L. & PINPIN & Intensity & 0.24 & 0.34 & 0.3 & 0.56 \\
\hline Pinus sylvestris L. & PINSYL & Intensity & 0.27 & 0.51 & 0.35 & 0.57 \\
\hline Populus tremula L. & POPTRE & Intensity & 0.29 & 0.29 & 0.34 & 0.59 \\
\hline Quercus ilex L. & QUEILE & Intensity & 0.26 & 0.48 & 0.35 & 0.40 \\
\hline Quercus petraea Liebl. & QUEPET & Intensity & 0.29 & 0.77 & 0.4 & 0.57 \\
\hline Quercus pyrenaica Willd. & QUEPYR & Intensity & 0.26 & 0.26 & 0.32 & 0.26 \\
\hline Quercus pyrenaica Willd. & QUEPYR & Intensity + SAC & 0.26 & 0.26 & 0.29 & 0.57 \\
\hline Quercus robur L. & QUEROB & Intensity & 0.26 & 0.38 & 0.33 & 0.61 \\
\hline Quercus suber L. & QUESUB & Intensity & 0.33 & 0.33 & 0.34 & 0.73 \\
\hline
\end{tabular}


bioRxiv preprint doi: https://doi.org/10.1101/2020.10.30.362087; this version posted November 1, 2020. The copyright holder for this

preprint (which was not certified by peer review) is the author/funder, who has granted bioRxiv a license to display the preprint in perpetuity. It is made available under aCC-BY-NC-ND 4.0 International license.

Figure 3: First and third columns show the predicted mortality occurrence (GLMM) and second and fourth columns are the predicted intensity of mortality (ZTNBGLMM) for the twenty species. Blues dots correspond to mortality predictions values lower than the first quartile (lowest values), green dots represent values ranging from the first to the third quartile (medium values) and red dots represent values higher than the third quartile (highest values) (Table S10). Light grey areas display species distribution ranges.
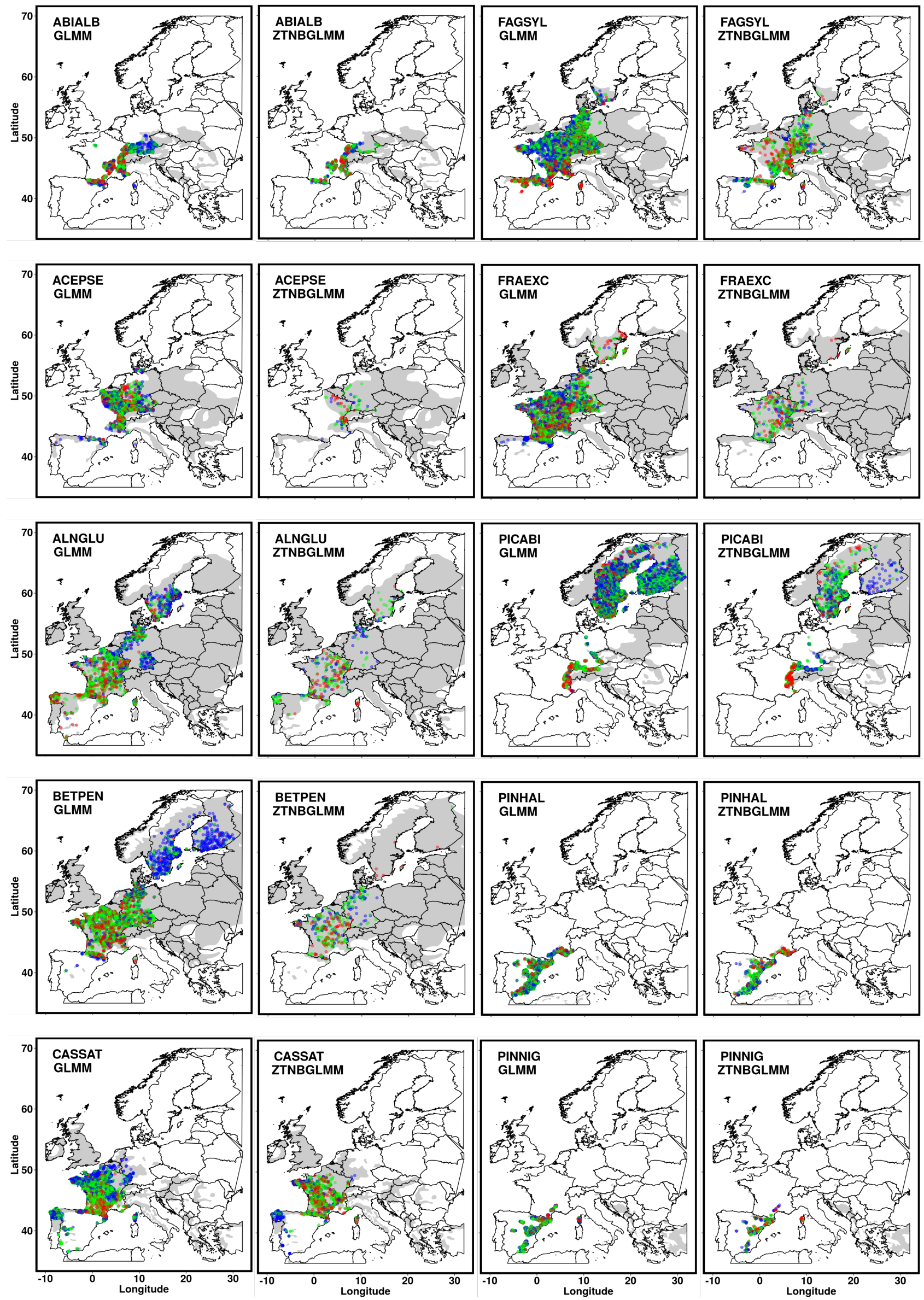

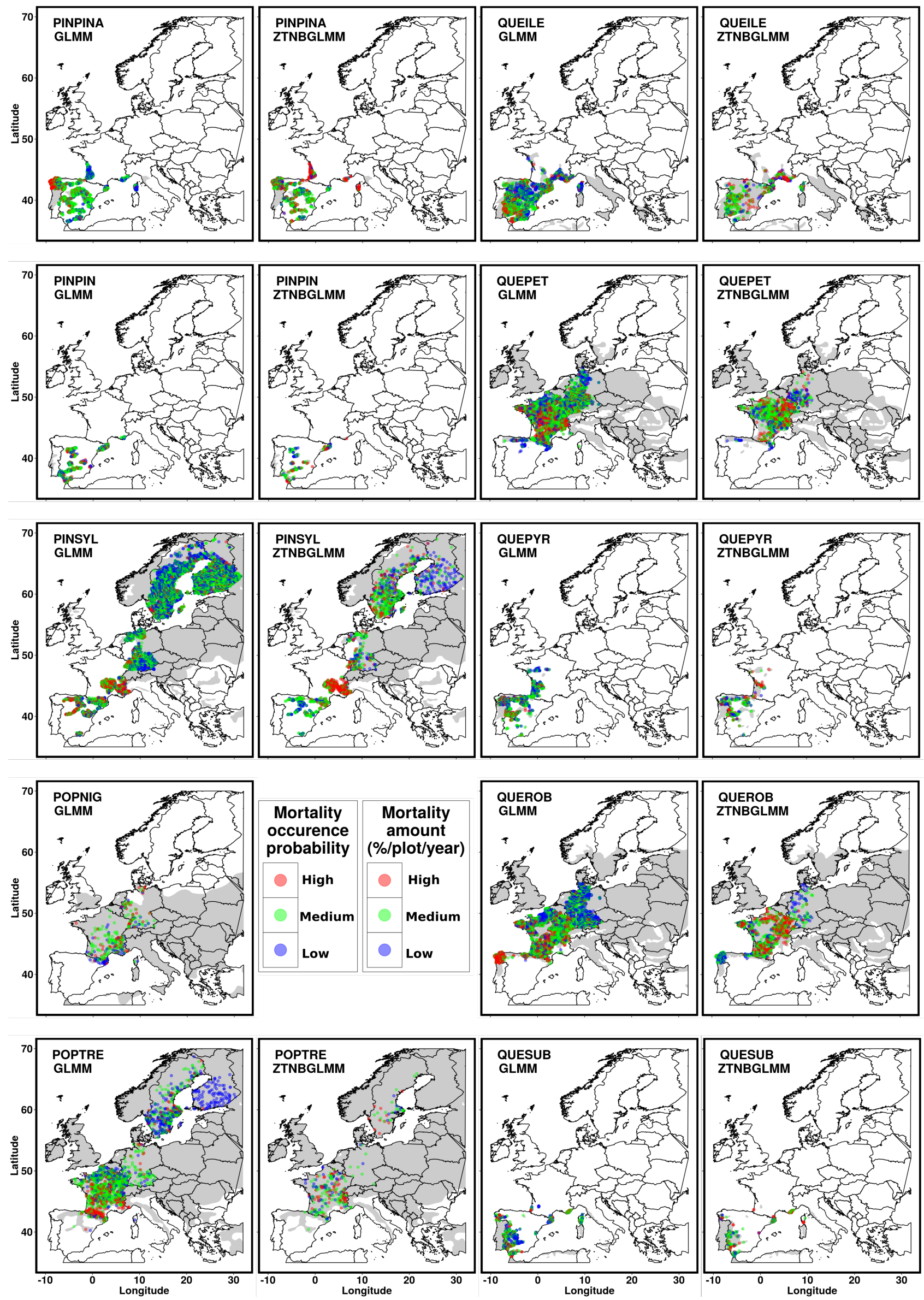